\title{
Systematic overview of neuroanatomical differences in ADHD: Definitive evidence
}

\author{
Bruno Bastos Vieira de Melo, ${ }^{\mathrm{a}, \mathrm{c}}$ \\ Maria João Trigueiro ${ }^{\text {, }}$ \\ Pedro Pereira Rodrigues ${ }^{\mathrm{b}}$ \\ ${ }^{a}$ Occupational Therapy Department, Higher School of Health, Polytechnic Institute of Porto, Porto, Portugal; \\ ${ }^{\mathrm{b} C I N T E S I S ~ \& ~ C o m m u n i t y ~ M e d i c i n e, ~ I n f o r m a t i o n ~ a n d ~ H e a l t h ~ D e c i s i o n ~ S c i e n c e s ~ D e p a r t m e n t, ~ F a c u l t y ~ o f ~ M e d i c i n e, ~}$ \\ University of Porto, Porto, Portugal; 'Faculty of Education Sciences, University of Vigo
}

\section{ABSTRACT}

Objectives: This article seeks to identify neuroanatomical differences in ADHD through an overview of systematic reviews that report encephalic differences compared to a control group in volume, area, activation like-lihood or chemical composition.

Methods: We conducted a systematic search using Cochrane guidelines and PRISMA criteria in PubMed, Scopus, Web of Science, Cochrane Database of Systematic Reviews and Database of Abstracts of Reviews of Effects. Results: Results revealed broad encephalic involvement that includes a functional frontal and cingulate hypoactivation and structural differences in corpus callosum, cerebellum and basal nuclei.

Conclusions: ADHD symptoms might be due to a multi-network unbalanced functioning hypothesis.

Attention-deficit hyperactivity disorder (ADHD) is one of the most common neurodevelopmental disorders (Polanczyk, Salum, Sugaya, Caye, \& Rohde, 2015). Although no biomarkers have been linked, neuroanatomical differences have been one of the most investigated topics for several decades (Tannock, 1998), providing support for several, yet inconclusive large-scale brain network implications (Castellanos \& Proal, 2012) and models (Kofler et al., 2013; Sonuga-Barke, 2005). Neuroimaging developments and new methods have increased our understanding of the underlying neurobiology of ADHD (Rubia, Alegria, \& Brinson, 2014a). We have identified 94 reviews related to ADHD neuroanatomy: 54 qualitative reviews and 40 systematic reviews (26 with meta-analysis). Given this volume of scientific information, we aimed to identify the neuroanatomical differences in ADHD through an overview of systematic reviews that report encephalic differences in terms of volume, area, activation likelihood or chemical composition.

\section{Materials and methods}

This review was conducted following the guidelines from the Cochrane Handbook for Systematic Reviews of Interventions (The Cochrane Collaboration, 2011). Other suggestions were also considered (Booth et al., 2011; Smith, Devane, Begley, \& Clarke, 2011; The Joanna Briggs Institute, 2014). The search method was systematic and sought to minimize the exclusion of relevant reviews (Montori, Wilczynski, Morgan, \& Haynes, 2005; Sampson et al., 2009; Smith et al., 2011; The Cochrane Collaboration, 2011; Wilczynski \& Haynes, 2007). Reviewed abstracts and full-text articles were selected against a set of inclusion criteria and quality criteria by PRISMA Statement (Moher 
et al., 2015). Discrepancies were resolved by consensus among two investigators. No protocol or overview was identified to be similar to the methods applied in this overview.

\section{Criteria for inclusion}

Systematic reviews that used an imaging diagnostic technique to report functional or structural neuroanatomical differences between ADHD without comorbidity and normal controls, were included. English, Spanish, Italian, French, and Portuguese languages were included. No date restriction was applied.

\section{Search methods for identification of reviews}

An online systematic search was conducted on December 2015 in PubMed, Scopus, Web of Science, Cochrane Database of Systematic Reviews and Database of Abstracts of Reviews of Effects. Two queries were used: 1) "((((adhd[Title/Abstract] OR hyperactivity[Title/Abstract])) AND ("meta analysis"[Title/Abstract] OR "meta analytic"[Title/Abstract] OR "systematic review"[Title/Abstract])) NOT (rat[Title/Abstract] OR autism[Title/Abstract] OR "brain injury"[Title/Abstract] OR cardiac [Title/Abstract] OR stroke[Title/Abstract]))" and when mesh terms were available: 2)“(“Review"[Publication Type] OR "Review Literature as Topic"[Mesh] OR "Meta-Analysis as Topic"[Mesh] OR "Meta-Analysis"[Publication Type])) AND "Attention Deficit Disorder with Hyperactivity" [Mesh]". This search was updated monthly and no additional reviews were found until the final search conducted on April 23, 2017.

\section{Data collection, analysis and synthesis}

Search results were imported to Mendeley ("Mendeley desktop," 2016) and duplicates were excluded. Retrieved results were subject to two levels of screening: title/abstract and full text. Additional reviews identified in full text analysis were included. The PRISMA 27-item criteria checklist was applied to all reviews that met our inclusion criteria and information was extracted related to: author; year; objectives; search methods; comparability of included studies; assessment of publication bias and heterogeneity; reported brain differences; statistical outcomes; qualitative aggregated results. In functional magnetic resonance imaging (fMRI), results corrected for multiple comparison in the inference on activation likelihood estimation (ALE) data were extracted (Eickhoff, Bzdok, Laird, Kurth, \& Fox, 2012; Laird et al., 2009).

Extracted data were organized in four tables: summary of characteristics of included systematic reviews (Table 1); summary of quality criteria of included systematic reviews (Table 2); major findings (Table 3); main recommendations (Table 4). Eight additional supplemental tables were also organized: assessment of reviews that met the inclusion criteria on the PRISMA statement checklist (Supplemental Table S1); summary of characteristics of excluded systematic reviews (Supplemental Table S2); summary of quality criteria of excluded systematic reviews (Supplemental Table S3); overlap trial calculation (Supplemental Table S4); overlap trial calculation in fMRI systematic reviews (Supplemental Table S5); overview of neuroanatomical differences in children with ADHD (Supplemental Table S6); overview of neuroanatomical differences in adults with ADHD (Supplemental Table S7); overview of neuroanatomical differences in children and adults with ADHD (Supplemental Table S8).

Although they had a common objective, the divergence in the type of results between systematic reviews did not allow for a quantitative analysis. A qualitative synthesis of neuroanatomical functional and structural differences in ADHD vs normal controls is provided (Schunemann et al., 2008; Smith et al., 2011; The Cochrane Collaboration, 2011). 
Table 1. Summary of characteristics of included systematic reviews.

\begin{tabular}{|c|c|c|c|c|}
\hline $\begin{array}{l}\text { Author(s) of } \\
\text { review and year } \\
\text { published }\end{array}$ & Objective of review & $\begin{array}{c}\text { Total number of studies } \\
\text { included in this review } \\
\text { (number of studies by } \\
\text { technique) }\end{array}$ & $\begin{array}{l}\text { Range of years } \\
\text { of studies } \\
\text { included in the } \\
\text { review }\end{array}$ & $\begin{array}{l}\text { Total number of } \\
\text { participants } \\
\text { (number of } \\
\text { participants by } \\
\text { technique) } \\
\end{array}$ \\
\hline $\begin{array}{l}\text { Valera et al. } \\
\quad(2007)\end{array}$ & $\begin{array}{l}\text { To identify structural volume/area } \\
\text { differences between ADHD and normal } \\
\text { controls }\end{array}$ & $21 \mathrm{MRI}$ & 1990-2004 & $1163 \mathrm{MRI}$ \\
\hline $\begin{array}{l}\text { Ellison-Wright } \\
\text { et al. (2008) }\end{array}$ & $\begin{array}{l}\text { To identify structural grey matter } \\
\text { differences between ADHD and normal } \\
\text { controls }\end{array}$ & 6 MRI-VBM & 2001-2007 & 257 MRI-VBM \\
\hline $\begin{array}{l}\text { Durston et al. } \\
\qquad(2009)\end{array}$ & $\begin{array}{l}\text { To identify structural, functional and } \\
\text { genetic differences between ADHD and } \\
\text { normal controls }\end{array}$ & 86 (45 MRI; 41 fMRI) & 1991-2009 & Not reported \\
\hline $\begin{array}{l}\text { Samuele Cortese } \\
\text { et al. (2012) }\end{array}$ & $\begin{array}{l}\text { To identify functional differences } \\
\text { between children/adults/children and } \\
\text { adults with ADHD and normal controls } \\
\text { in executive function, inhibitory } \\
\text { control, attention and memory tasks }\end{array}$ & $55 \mathrm{fMRI}$ & 2005-2011 & $1542 \mathrm{fMRI}$ \\
\hline Aoki et al. (2013) & $\begin{array}{l}\text { To identify metabolite level differences } \\
\text { between ADHD and normal controls } \\
\text { and its age-related changes }\end{array}$ & 16 MRS & 2001-2010 & $505 \mathrm{MRS}$ \\
\hline Chen et al. (2016) & $\begin{array}{l}\text { To identify white matter differences } \\
\text { between ADHD and normal controls } \\
\text { using MRI-DTI-TBSS }\end{array}$ & 10 MRI-DTI-TBSS & 2009-2015 & 947 MRI-DTI \\
\hline
\end{tabular}

Abbreviations: ADHD, Attention-deficit hyperactivity disorder; DTI, diffusion tensor imaging; fMRI, functional magnetic resonance imaging; MRI, magnetic resonance imaging; MRS, magnetic resonance spectroscopy; TBSS, tract-based spatial statistics; VBM, voxel-based morphometry.

Table 2. Summary of quality criteria of included systematic reviews.

\begin{tabular}{|c|c|c|c|c|c|}
\hline $\begin{array}{l}\text { Author(s) of } \\
\text { review and year } \\
\text { published }\end{array}$ & $\begin{array}{l}\text { (i) Types of studies; (ii) } \\
\text { types of participants }\end{array}$ & $\begin{array}{l}\text { Database(s) searched: } \\
\text { publication years searched: } \\
\text { date the search was done }\end{array}$ & $\begin{array}{l}\text { Comparability of } \\
\text { included studies }\end{array}$ & $\begin{array}{l}\text { Assessment } \\
\text { of } \\
\text { publication } \\
\text { bias }\end{array}$ & $\begin{array}{l}\text { Assessment } \\
\text { of } \\
\text { heterogeneity }\end{array}$ \\
\hline $\begin{array}{l}\text { Valera et al. } \\
\quad(2007)\end{array}$ & $\begin{array}{l}\text { (i) Not reported; (ii) } \\
\text { ADHD children vs } \\
\text { controls }\end{array}$ & $\begin{array}{l}\text { PubMed e PsycINFO: no limit: } \\
\text { January } 2005\end{array}$ & $\begin{array}{l}\text { Table comparing } \\
\text { studies provided }\end{array}$ & $\begin{array}{l}\text { Statistical } \\
\text { assessment }\end{array}$ & $\begin{array}{l}\text { Statistical } \\
\text { assessment }\end{array}$ \\
\hline $\begin{array}{l}\text { Ellison-Wright } \\
\text { et al. (2008) }\end{array}$ & $\begin{array}{l}\text { (i) Not reported; (ii) } \\
\text { ADHD children vs } \\
\text { controls }\end{array}$ & PubMed: no limit: March 2008 & ALE analysis & $\begin{array}{l}\text { Not } \\
\text { reported }\end{array}$ & Not reported \\
\hline $\begin{array}{l}\text { Durston et al. } \\
\text { (2009) }\end{array}$ & $\begin{array}{l}\text { (i) Not reported; (ii) } \\
\text { ADHD children and } \\
\text { adults vs controls }\end{array}$ & $\begin{array}{l}\text { PubMed and ISI Web of } \\
\text { Science: not reported: not } \\
\text { reported }\end{array}$ & $\begin{array}{l}\text { Table comparing } \\
\text { studies provided }\end{array}$ & $\begin{array}{l}\text { Not } \\
\text { reported }\end{array}$ & Not reported \\
\hline $\begin{array}{l}\text { Samuele Cortese } \\
\text { et al. (2012) }\end{array}$ & $\begin{array}{l}\text { (i) Not reported; (ii) } \\
\text { ADHD vs controls; ADHD } \\
\text { children vs controls; } \\
\text { ADHD adults vs controls }\end{array}$ & $\begin{array}{l}\text { PubMed, PsycINFO, Ovid } \\
\text { Medline }^{\circledast}, \text { Embase, Web of } \\
\text { Science, Eric, Cinhal e } \\
\text { "NeuroSynth": 2005-2011: } \\
\text { June } 2011\end{array}$ & $\begin{array}{l}\text { Table comparing } \\
\text { studies provided; } \\
\text { ALE analysis }\end{array}$ & $\begin{array}{l}\text { Not } \\
\text { reported }\end{array}$ & $\begin{array}{l}\text { Not clearly } \\
\text { reported }\end{array}$ \\
\hline Aoki et al. (2013) & $\begin{array}{l}\text { (i) Not reported; (ii) } \\
\text { ADHD vs controls }\end{array}$ & $\begin{array}{l}\text { Medline, Mebase and Web of } \\
\text { Science: 1980-2012: not } \\
\text { reported }\end{array}$ & $\begin{array}{l}\text { Table comparing } \\
\text { studies provided; } \\
\text { effect size }\end{array}$ & $\begin{array}{l}\text { Statistical } \\
\text { assessment }\end{array}$ & $\begin{array}{l}\text { Statistical } \\
\text { assessment }\end{array}$ \\
\hline Chen et al. (2016) & $\begin{array}{l}\text { (i) Not reported; (ii) } \\
\text { ADHD vs controls }\end{array}$ & $\begin{array}{l}\text { PubMed, Web of Science, } \\
\text { Embase, Ebsco, Clinical Key } \\
\text { and Science Direct databases: } \\
\text { October 2015: not reported }\end{array}$ & $\begin{array}{l}\text { Table comparing } \\
\text { studies provided; } \\
\text { ALE analysis }\end{array}$ & $\begin{array}{l}\text { Not clearly } \\
\text { reported }\end{array}$ & Not reported \\
\hline
\end{tabular}

Abbreviations: ADHD, Attention-deficit hyperactivity disorder; ALE, activation likelihood estimation. 
Table 3. Major findings.

Major findings

- Reduced overall cerebral volume and specifically in the right hemisphere, frontal and parietal lobe, basal nuclei, globus pallidus, corpus callosum and cerebellum

- Frontal lobe hypoactivation, specifically in the precentral, middle and inferior frontal gyri

- Middle prefrontal cortex with increased levels of $\mathrm{N}$-acetylaspartate

- Corpus callosum white matter with fractional anisotropy reduction

- Other consistently reported brain regions with partially consistent activation patterns such as cingulate cortex, insula, basal nuclei, parietal, temporal and occipital lobes

Table 4. Main recommendations.

Main recommendations

- Despite the extensive literature, highly homogeneous trials with clearly reported participants and replicable methods are needed

- $\mathrm{ADHD}$ is clearly suggested to go beyond the frontoparietal network and dopaminergic system

- The hypothesis of an unbalanced multi-network neurofunctioning in ADHD indicates that a variety of skills could be compromised

- A multidisciplinary assessment should be addressed for diagnostic and occupational performance treatment approaches

- The broad encephalic involvement discussed could support ADHD models that conceptualize a systemic implication of the nervous system

\section{Results}

As shown in Figure 1, a total of 8,253 articles were initially retrieved. After removing duplicates and applying language restriction, 103 systematic reviews about ADHD were identified by reviewing title/abstract. A full-text analysis yielded 74 reviews about neuroanatomical differences of which 30 presented a systematic methodology including: computed axial tomography (CT); electroencephalography (EEG); event-related potential (ERP); fMRI; functional near-infrared spectroscopy (fNIRS); magnetic resonance imaging (MRI) with voxel-based morphometry (MRI-VBM), diffusion tensor imaging (MRI-DTI) and tract-based spatial statistics (MRI-DTITBSS); magnetic resonance spectroscopy (MRS); positron emission tomography (PET); resting state functional connectivity MRI ( $r$-fcMRI); single-photon emission computed tomography (SPECT); and transcranial magnetic stimulation (TMS). The consistency of structural and functional objectives allowed for the identification of 17 systematic reviews that aimed to identify the structural or functional neuroanatomical differences between ADHD and normal controls (Aoki, Inokuchi, Suwa, \& Aoki, 2013; Chen et al., 2016; Cortese et al., 2012; Dickstein, Bannon, Xavier Castellanos, \& Milham, 2006; Durston, de Zeeuw, \& Staal, 2009; Ellison-Wright, Ellison-Wright, \& Bullmore, 2008; Hart, Radua, Mataix-Cols, \& Rubia, 2012; Hart, Radua, Nakao, Mataix-Cols, \& Rubia, 2013; Hutchinson, Mathias, \& Banich, 2008; Lei et al., 2015; McCarthy, Skokauskas, \& Frodl, 2014; Paloyelis, Mehta, Kuntsi, \& Asherson, 2007; Perlov et al., 2009; Spencer, Uchida, Kenworthy, Keary, \& Biederman, 2014; Tannock, 1998; Valera, Faraone, Murray, \& Seidman, 2007; van Ewijk, Heslenfeld, Zwiers, Buitelaar, \& Oosterlaan, 2012).

Trials used in these 17 systematic reviews were pooled (Supplemental Table S4) so that the overlap could be analyzed and the PRISMA 27-item checklist was applied (Supplemental Table S1). We aimed not to repeat included trials and to prioritize higher PRISMA scores. If a partial or total overlap was identified, the following criteria were applied: 1) for the same imaging technique, reviews with exclusive trials were included; 2) for reviews with the same trials used, a quantitative analysis was preferred over a qualitative analysis; 3 ) for the same methodological analysis, reviews with higher PRISMA score were preferred. 


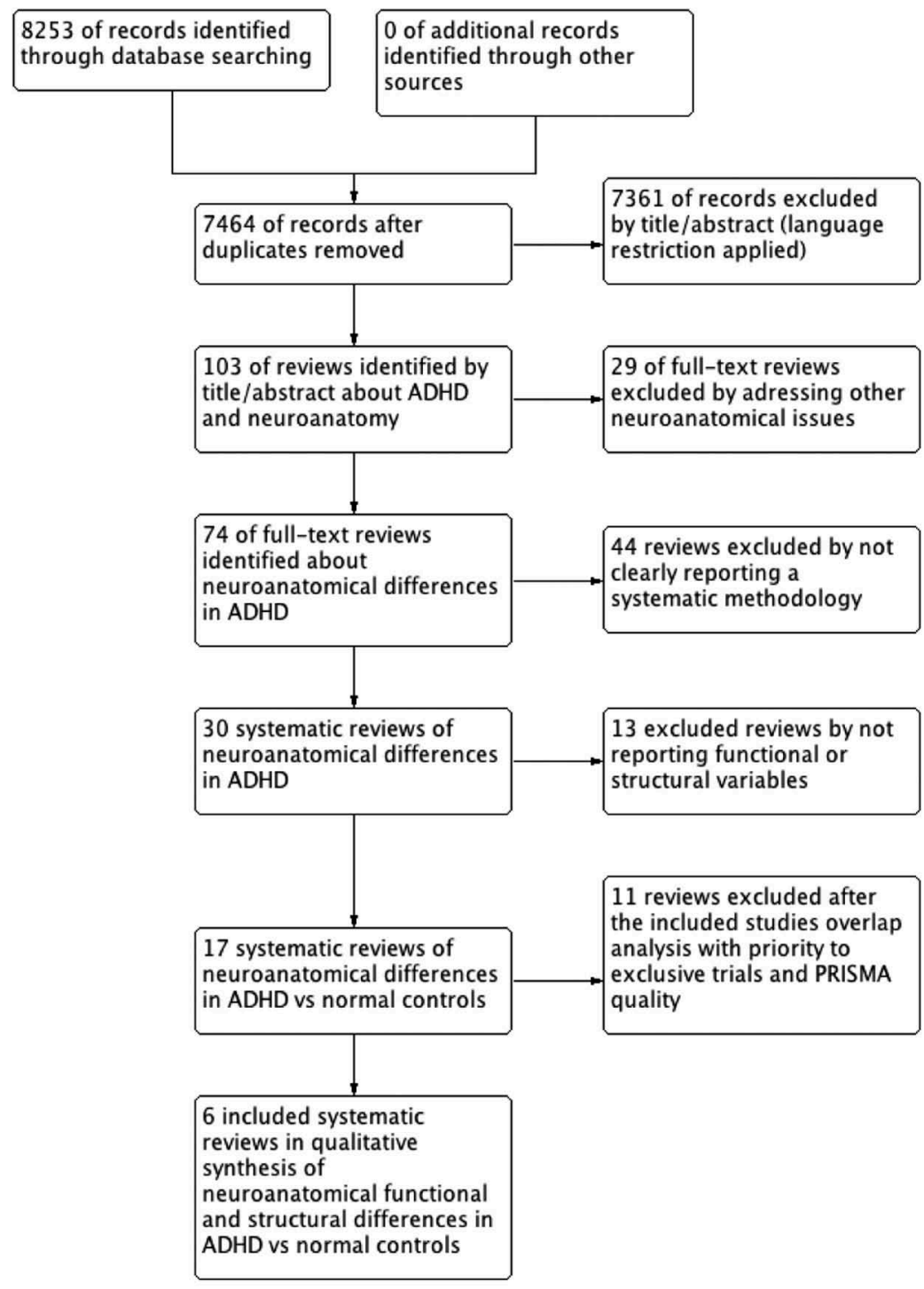

Figure 1. Flow diagram of included systematic reviews.

Therefore, 6 systematic reviews were included in this review covering 145 individual trials (out of the total 191 pooled trials) using MRI; MRI-VBM; fMRI; MRS and MRI-DTI-TBSS, from 1990 to 2015, with over 4144 participants (Table 1 and Supplemental Table S4).

\section{Overview of neuroanatomical differences in children with ADHD}

Table 3 refers to the main findings of this overview. For detailed results, please refer to Supplemental Tables S6-S8.

\section{Structural differences compared to controls}

There was a reduction in the total cerebral volume (Durston et al., 2009; Valera et al., 2007) and specific regions: right hemisphere (Valera et al., 2007); frontal lobe (Durston et al., 2009); parietal 
lobe, possibly explained by a reduced cortical thickness (Durston et al., 2009); basal nuclei in the right caudate (Durston et al., 2009; Valera et al., 2007) and putamen (Ellison-Wright et al., 2008); right globus pallidus (Ellison-Wright et al., 2008); corpus callosum in the splenium (Valera et al., 2007); and cerebellum hemispheres and vermis (Valera et al., 2007).

\section{Chemical neurometabolites compared to controls}

One included review (Aoki et al., 2013) reported a combined result of both children and adults with ADHD. Therefore, these results will be included in the children and adults section below.

\section{Functional differences compared to controls}

Frontal lobe with hypoactivation in the supplementary motor area (BA 6), bilateral middle superior frontal gyrus (BA 6, 9 e 46), precentral gyrus and inferior frontal gyrus (Cortese et al., 2012). In the parietal lobe, there is a right frontal area and right postcentral gyrus hypoactivation (BA 40) with a hyperactivation in the right angular gyrus and right subparietal sulcus (Cortese et al., 2012). In the temporal lobe there is hypoactivation in the right superior temporal gyrus (BA 22) (Cortese et al., 2012) and in the occipital lobe hyperactivation of the right middle occipital gyrus (BA 19) (Cortese et al., 2012). These alternate patterns of activation were most frequently observed in the cingulate cortex, insula and basal nuclei. In the cingulate cortex, hypoactivation occurred in the bilateral paracingulate gyrus (BA 32) and hyperactivation in the right middle and posterior cingulate (Cortese et al., 2012). In the insula, hyperactivation occurred in the right sub-operculum white matter, and in the basal nuclei bilateral hypoactivation in the putamen was identified (Cortese et al., 2012).

\section{Overview of neuroanatomical differences in adults with ADHD}

Structural differences compared to controls

None of the 17 analyzed reviews reported structural differences specifically in adult ADHD.

\section{Chemical neurometabolites compared to controls}

One included review (Aoki et al., 2013) reported a combined result of both in children and adults with ADHD. Therefore, these results will be included in the children and adults section below.

\section{Functional differences compared to controls}

Different activation patterns in the frontal and parietal lobe were observed: frontal lobe hypoactivation in the precentral and right middle frontal gyri and central sulcus (BA 10) and parietal hyperactivation in the right angular gyrus (Cortese et al., 2012).

\section{Overview of neuroanatomical differences in children and adults with ADHD}

\section{Structural differences compared to controls}

Fractional anisotropy reduction was observed in the occipital lobe and corpus callosum (splenium and tapetum) (Chen et al., 2016). None of the remaining reviews reported quantitative MRI data about children and adults with ADHD.

\section{Chemical neurometabolites compared to controls}

Increased levels of $\mathrm{N}$-acetylaspartate in the middle prefrontal cortex (Aoki et al., 2013). None of the remaining reviews reported quantitative MRS data about children and adults with ADHD.

\section{Functional differences compared to controls}

One included review (Cortese et al., 2012) reported aggregated results in both children and adult ADHD differences, but as the adult sample was significantly smaller, only results for children were included. 


\section{Discussion}

Overall, these results revealed broad encephalic involvement that involves the functional frontal lobe and cingulate hypoactivation and structural differences in corpus callosum, cerebellum and basal nuclei (Figure 2).

\section{Neurometabolites analysis implicate differences in the default mode and frontoparietal cognitive control network}

Our results show higher levels of $\mathrm{N}$-acetylaspartate (NAA) in the medial prefrontal cortex. NAA and $\mathrm{N}$-acetylaspartylglutamate (NAAG) are metabolically-linked substances that are synthesized by neurons as a function of their rate of glucose utilization and may reflect the state of regional activation (Aoki et al., 2013). This interpretation means that higher levels of NAA are not consistent with the functional fMRI frontal hypoactivation. However, in resting state functional results, there is a hyperactivation in these areas (Cortese et al., 2012) which in turn are consistent, since NAA results are reported in a resting state. In a resting state fMRI analysis (Posner, Park, \& Wang, 2014) these reported changes may be associated with both the default mode network-posterior cingulate cortex/ precuneus, middle prefrontal and inferior parietal cortices (Posner et al., 2014; Yeo et al., 2011) - and the frontoparietal cognitive control network-dorsal anterior cingulate cortex, supplementary motor area, dorsal lateral prefrontal cortex, inferior frontal junction, anterior insular, and posterior parietal cortices (Cole \& Schneider, 2007; Harding, Yücel, Harrison, Pantelis, \& Breakspear, 2015; Posner et al., 2014).

These higher levels of NAA are also not consistent with the lower NAA level reported by a qualitative analysis and its conclusion that ADHD may present a under-development of neuronal processes and synapses associated with attention (Perlov et al., 2009; Stanley et al., 2006). Quantitative results of higher levels of choline were also reported in the left striatum and right frontal lobe in children and in the bilateral anterior cingulate cortex in adults (Perlov et al., 2009). Choline signal is regarded as reflecting the turn-over of cell membranes and may be associated with energy metabolism and cholinergic neurotransmission. Significant increases in choline resonance are commonly observed in neurodegenerative disorders, ischemia, head trauma and cancer (Perlov et al., 2009). The precise meaning of altered choline-signals in MRS is not yet resolved (Aoki et al., 2013; Perlov et al., 2009). The same may be applied to the levels of glutamine/glutamate (referred to
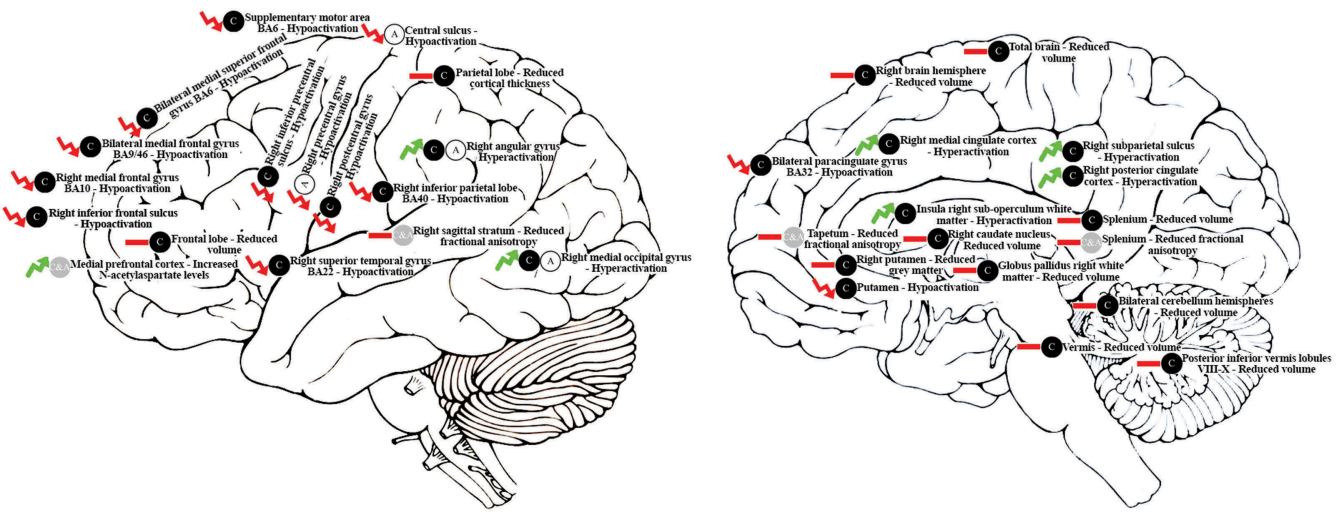

Figure 2. Neuroanatomical differences identified in ADHD. 
collectively as "Glx"), a marker of glutamatergic system, which show inconsistent results (Aoki et al., 2013; Perlov et al., 2009; Spencer et al., 2014).

Taken together, increased neurometabolites levels emerge as significant, but are not yet clearly understood. If these levels are to be interpreted as a marker of neuronal processes development, they may not support the concept that ADHD might have a prefrontal cortex underdevelopment. If interpreted as a sign of activation, they may report a prefrontal cortex resting-state hyperactivation in one of the main regions associated with the default mode network, which is supposed to be observed in a resting state. If interpreted as a possible neuronal functional disruption in the reported areas, they may represent a possible unbalance in the default mode network and frontoparietal network which undergird attentional skills (Posner et al., 2014). Only by clearly converging similar methodological fMRI and MRS studies might it be possible to clarify these observed differences.

\section{Additional analysis using resting state EEG might not be consistent with neurometabolites levels}

EEG reviews were excluded as they did not report specific neuroanatomical regions as specified in the included methods. But as they were one of the first systematic methods used to measure resting-state and functional cortical activity, their main results may help interpret the previous NAA results. Apart from the technical limitations and some inconsistent results, the EEG results indicate an increased frontal theta wave pattern (Castellanos \& Acosta, 2002; Sigi Hale, Hariri, \& McCracken, 2000; Tannock, 1998; Willis \& Weiler, 2005), a posterior increase of delta waves with decrease of alpha and beta activity (Willis \& Weiler, 2005) and increased theta/beta ratio (Snyder \& Hall, 2006).

These EEG results supported two previous ADHD interpretations: low cortical arousal and delayed cortical maturation. The low cortical arousal interpretation was supported by the frontal increase of slow wave pattern (delta and theta), decrease of fast wave pattern (alpha e beta) and increased theta/beta ratio (Castellanos \& Acosta, 2002; Loo \& Makeig, 2012; Rudo-Hutt, 2015; Sigi Hale et al., 2000; Tannock, 1998; Tye, McLoughlin, Kuntsi, \& Asherson, 2011; Willis \& Weiler, 2005). In terms of coherence (calculated as the cross-correlation in the frequency domain between two EEG time points, measured simultaneously at different scalp locations), ADHD showed frontal hypercoherence (Sigi Hale et al., 2000; Tye et al., 2011) thought to indicate reduced cortical differentiation (Tye et al., 2011; Willis \& Weiler, 2005). This fact supported both interpretations since this hypercoherence is relative to slow waves in the frontal region and this lower cortical differentiation tends to normalize with increasing age (Loo \& Makeig, 2012; Rudo-Hutt, 2015; Tye et al., 2011; Willis \& Weiler, 2005).

Different EEG frequencies have also been implicated in specific mental/physiological states consistent with ADHD: delta waves with deep sleep; theta with the intake of sensory information, spatial memory and positively associated with low arousal; alpha waves with wakeful relaxation, possibly with a synchronization of neuronal processes across the brain, negative association with arousal and positive association with externalizing behavior; beta waves with working memory, mental activation and focus; gamma waves with alertness and sensory stimulation; and theta/beta ratio with a negative association to reaction time (Loo \& Makeig, 2012; Rudo-Hutt, 2015). The hippocampus has also been implicated with the theta rhythm and thalamo-cortical circuits with alpha rhythm (Willis \& Weiler, 2005)

Therefore, the NAA findings indicating frontal hyperactivation are not consistent with previous EEG results. However, these EEG results are consistent with the fMRI results of a frontal hypoactivation and posterior hyperactivation tendency. EEG findings are mostly based on a resting state with eyes open and closed (Loo \& Makeig, 2012; Rudo-Hutt, 2015; Tye et al., 2011), but functional state is also possible (Willis \& Weiler, 2005), so it is expected that some EEG results might represent a combination of both states. This EEG/fMRI consistency might also be due to the 
fact that both techniques have decades of investigation and MRS results related to ADHD are in the early stages, which may explain the inconsistent findings. Therefore, it is not yet possible to draw firm conclusions about elevated NAA results in ADHD.

\section{Combined analysis of EEG/ERP and fMRI results may confirm default mode and frontoparietal cognitive control network implication}

The previous assumption has also been identified in simultaneous EEG/fMRI evaluation where a high arousal pattern (decreased delta and theta with increased alpha and beta) might be associated with this brain network (Hlinka, Alexakis, Diukova, Liddle, \& Auer, 2010; Rudo-Hutt, 2015) and other fMRI resting-state results (Konrad \& Eickhoff, 2010; Paloyelis et al., 2007; Posner et al., 2014; Yeo et al., 2011).

Given the balanced functioning between the default mode and frontoparietal cognitive control networks, these EEG results might implicate both networks. ERP results might support this consideration as they report differences in stimulus or task response. ADHD showed a possible difference in central arousal patterns with subcortical hypoactivation (Castellanos \& Acosta, 2002; Tannock, 1998) specially in the frontal (Sigi Hale et al., 2000) and dorsolateral and anterior cingulate regions (Swanson et al., 1998), with poorer performance on attentional and inhibition tasks (Tye et al., 2011). Once these results are reported in a functional state, the dorsal anterior cingulate cortex is expected to be more active through the frontoparietal cognitive control network functioning. So, this hypoactivation may also implicate this network. This argument is consistent with other results (Bush, Valera, \& Seidman, 2005; Cherkasova \& Hechtman, 2009; Cortese et al., 2012; Cubillo, Halari, Smith, Taylor, \& Rubia, 2012; Durston, 2003; Emond, Joyal, \& Poissant, 2009; Kelly, Margulies, \& Castellanos, 2007; Paloyelis et al., 2007; Posner et al., 2014; Weyandt, Swentosky, \& Gudmundsdottir, 2013) and may be supported by the combination of EEG/ERP and fMRI results, because of the possible relationship between alpha and theta waves with cognitive control networks (Carp \& Compton, 2009; Cooper et al., 2015). Therefore, the attentional difficulties observed in ADHD might be due not only to the default mode network but also by the inconsistent activation/deactivation balance with the frontoparietal cognitive control network.

\section{Functional fMRI differences may support other neural networks}

Our fMRI overview results reported differences in other brain regions that are not as expressive as the frontal hypoactivation:

- Parietal lobe results are partially consistent with other reviews that reported a hypoactivation in the right inferior parietal lobe (McCarthy et al., 2014) and that also included the right superior parietal area, left precuneus (BA 3, 5 e 7) and extended to the fusiform gyrus (Dickstein et al., 2006; Lei et al., 2015). A hyperactivation in this same area was not identified by one included review (Cortese et al., 2012) but was identified in other reviews on inhibitory motor task (Lei et al., 2015) along with the right postcentral gyrus (BA 2) (Dickstein et al., 2006; Lei et al., 2015); - Temporal lobe hypoactivation in the right superior temporal gyrus (BA 22) (Cortese et al., 2012) is consistent with other findings, that also added the left superior temporal gyrus (BA 38) (Dickstein et al., 2006);

- Occipital lobe hyperactivation in the right middle occipital gyrus (BA 19) (Cortese et al., 2012) is not consistent with other findings that observed a hypoactivation in this same area (Dickstein et al., 2006), but is consistent with the adult results (Lei et al., 2015; McCarthy et al., 2014);

- Cingulate cortex, insula and basal nuclei are consistent as reported brain regions, but partially consistent in terms of activation pattern (Dickstein et al., 2006; Lei et al., 2015). 
Taken together, these results point to an extended network implication that goes beyond the frontal networks, and that are translated into changes in observable skills. This argument has also been considered in earlier fMRI reviews (Cherkasova \& Hechtman, 2009; Durston, 2003; Kelly et al., 2007). Combining our results with the seven-network parcellation of the human cortex by Yeo et al. (2011), the other five-networks may also be implicated: dorsal attention, ventral attention, somatomotor, visual and limbic (Yeo et al., 2011).

Our results showed a hypoactivation pattern along the ventral attention network and a partial hypoactivation along the dorsal attention network. As these interconnected networks are respectively responsible for monitoring salient stimuli and mediating goal-directed top-down executive control processes, its relationship to ADHD core symptoms is therefore relevant (Castellanos \& Proal, 2012; Hart et al., 2013; Paloyelis et al., 2007). These frontal hypoactivation results are implied in inhibitory control tasks (Dickstein et al., 2006; Lei et al., 2015; McCarthy et al., 2014) and are consistent with previous results that also identified a hypoactivation pattern in the frontal and precentral gyrus bilateral (BA 6, 8, 9, 10 e 47) (Dickstein et al., 2006) and left middle frontal gyrus (McCarthy et al., 2014).

The somatomotor network, represented in our overview as a hypoactivation in the supplementary motor area and precentral, postcentral and right superior temporal gyri, is probably implicated in reported ADHD motor and body scheme skills (García Murillo, Cortese, Anderson, Di Martino, \& Castellanos, 2015; Kaiser, Schoemaker, Albaret, \& Geuze, 2015; Paloyelis et al., 2007).

The visual network, represented in our results as an occipital hyperactivation that along with the dorsal attentional network implication (which mediates goal-directed, top-down executive control processes, particularly in reorienting attention during visual attentional functioning) might influence both attention and visual skills (Brown, Roth, \& Katz, 2015; Castellanos \& Proal, 2012; Cortese et al., 2012; Germano, Pinheiro, Okuda, \& Capellini, 2013; Mullane \& Klein, 2008; Yeo et al., 2011).

The limbic network, represented in our results by a hyperactivation in the posterior cingulate cortex, the hippocampus implication (mentioned previously in EEG results) and splenium (mentioned later in MRI discussion), are probably associated with the ADHD emotional regulation skills (Graziano \& Garcia, 2016; Rubia, 2011; Yeo et al., 2011).

\section{Structural differences in the corpus callosum and striatum-cerebellar networks support a multiple neural network implication}

Reported structural differences may support a multi-network hypothesis in ADHD, as they identified further regions regarding volumetric reductions in total and frontal brain, right hemisphere, striatum, caudate nucleus, putamen, globus pallidus, vermis, and cerebellar hemispheres. No increased volumetric results were reported. These MRI results are consistent with previous CT studies (Faraone \& Biederman, 1998; Giedd, Blumenthal, Molloy, \& Castellanos, 2001; Sigi Hale et al., 2000) and grey matter (soma, dendrite, synapse, glial cells) differences in the putamen and globus pallidus, which in turn are consistent with PET/SPECT results of reduced dopamine transporter levels in the basal nuclei (Rubia et al., 2014a; Zimmer, 2009). These differences might implicate the dopaminergic system through the representation of its regions (EllisonWright et al., 2008; Frodl \& Skokauskas, 2012; Nakao, Radua, Rubia, \& Mataix-Cols, 2011), functional pathways (Durston et al., 2009; Swanson et al., 2007) and the reward system in the cortical-basal nuclei network, striatum and pre-frontal areas (Mowinckel, Pedersen, Eilertsen, \& Biele, 2015; Paloyelis et al., 2007; Plichta \& Scheres, 2014; Seymour, Reinblatt, Benson, \& Carnell, 2015).

Specifically, the cerebellar and basal nuclei structural involvement may further support this hypothesis. Structural results are consistent with PET/SPECT results that, similarly to the fMRI results, reported changes in ADHD should go beyond the dopaminergic system (Rubia et al., 2014a; Spencer et al., 2014; Zimmer, 2009) and contribute to ADHD behaviors (Pappa, Mileva-Seitz, 
Bakermans-Kranenburg, Tiemeier, \& van IJzendoorn, 2015; Rogers \& De Brito, 2015). These structural results could represent an implication of the fronto-striatum-parietal-cerebellar networks (Paloyelis et al., 2007; Rubia et al., 2014a; Weyandt et al., 2013), as fronto-striato-cerebellar networks are related to the limbic system and emotional regulation (Graziano \& Garcia, 2016; Herrmann, Biehl, Jacob, \& Deckert, 2010; Seymour et al., 2015; Yeo et al., 2011), but also, cortico-striatothalamic-cortical circuitry that mediates sensorimotor, cognitive and limbic functions (Posner et al., 2014), thalamo-cortical circuit that are thought to be the generators for the alpha rhythm (Willis \& Weiler, 2005) and structural brain connectomics with regional changes distributed in the sensorimotor, attention, default-mode, striatum and cerebellum regions (Cao, Shu, Cao, Wang, \& He, 2014).

Structural striatum and cerebellar differences, taken together with functional differences regarding frontal, cingulate and supplementary areas, are consistent with changes in the inhibitory control networks (Aron \& Poldrack, 2005; Hart et al., 2012, 2013; Noreika, Falter, \& Rubia, 2013; Paloyelis et al., 2007; Rubia et al., 2014a), both in motor and impulsive behaviors (Boonstra, Oosterlaan, Sergeant, \& Buitelaar, 2005; Kofler et al., 2013; Lansbergen, Kenemans, \& van Engeland, 2007; Lei et al., 2015; Lijffijt, Kenemans, Verbaten, \& van Engeland, 2005; McCarthy et al., 2014; Pauli-Pott \& Becker, 2015; Rubia, Halari, Christakou, \& Taylor, 2009; Schwartz \& Verhaeghen, 2008; Seymour et al., 2015; van Mourik, Oosterlaan, \& Sergeant, 2005). These inhibitory network differences are consistent with MRS results where ADHD showed lower cortical inhibition that may support GABAergic system compromise (Bunse et al., 2014; Dutra, Baltar, \& Monte-Silva, 2016; Rothwell, Day, Thompson, \& Kujirai, 2009).

White matter results, with fractional anisotropy reduction (that represent regional myelination levels, fiber crossing, axonal density and average axonal diameter) along the splenium, sagittal stratum and tapetum, implicate the largest white matter bundle that connects the bilateral cerebral hemispheres (Chen et al., 2016; van Ewijk et al., 2012) and thus might influence inter-hemispheres, anterior/posterior functioning such as limbic, attentional and visual networks through longitudinal and inferior fronto-occipital fasciculus. Other regions have been identified but qualitative methodology and study inclusion might account for the reported differences (Mana, Paillere Martinot, \& Martinot, 2010; Matthews, Nigg, \& Fair, 2013; Rubia, Alegria, \& Brinson, 2014b; Van Ewijk et al., 2012; Weyandt et al., 2013). Our results are based on the largest (studies and participants) quantitative review (Chen et al., 2016).

\section{Overall completeness and applicability of evidence}

Our search method with two queries, full-text search of additional reviews and no limit on year of publication was an attempt to minimize any loss of relevant studies. Inevitably we missed any review that was not indexed in the reported databases. Once the criteria of reported neuroanatomical regions excluded methods such as EEG and PET/SPECT, we included the relevant qualitative results in our discussion. The overlap analysis with the top priority not to duplicate trials led to an exclusion of some individual trials (46 out of 191). We attempted to include them in our discussion when their qualitative results were separately reviewed.

With our criteria for inclusion, we have selected some of the most investigated imaging techniques in ADHD (MRI, MRI-DTI, fMRI and MRS) with a higher number of included studies and PRISMA criteria. To our knowledge, in this area of investigation, the present study is the only overview of systematic reviews to itself use a systematic methodology.

\section{Quality of the evidence and potential biases in the overview process}

Additional limitations should be noted: aggregated results of fMRI reviews are reported using trials with functional tasks that are not fully described making it impossible to identify different methods, variations and the individual contribution of each task to the final effect size. Brain regions and tasks 
that are previously selected might create an unbalanced focus on imaging studies and therefore reported neuroanatomical differences. Different nosological classifications might have led to unequal participants, both in terms of different versions of diagnostic classification systems and associated comorbidity. Medicated/medicated-naive participants were not always clearly reported. ALE fMRI results might create a different result in terms of whether a method of correcting for multiple comparison in the inference on ALE data is used or not (Cortese et al., 2012; Eickhoff et al., 2012; Laird et al., 2009). In the included trials, it was impossible to determine age, gender,and comorbidity tendencies that might account for asymmetrical participants' characteristics.

\section{Authors' conclusion}

ADHD and neurofunctional understanding combines two complex subjects with technical and conceptual limitations that despite extensive literature still requires intense debate. We tried to contribute by addressing this topic with a systematic approach that included the most consistent neuroanatomical imaging methods. Overall these results point to a broader neurofunctional implication in ADHD that clearly goes beyond the frontoparietal network and dopaminergic system. Thus, ADHD presents itself as a neurodevelopmental disorder with a multi-network/neurochemical implication. This hypothesis is consistent both in neuroimaging results and in behavior patterns, since this multi-network hypothesis is consistent with its translation to multiple implications in cognitive, emotional regulation, motor, sensory-perceptual, and social skills.

\section{Implications for practice}

This broader multi-network neurofunctional concept, that possibly translates into a multi-skill compromise, highlights the importance of a first level multidisciplinary diagnostic and treatment approach followed by a second level multidisciplinary assessment of how these core symptoms impact functional and occupational performance.

\section{Implications for research}

Neurofunctional and anatomical differences in ADHD are one of the most studied topics in the past decades with hundreds of reviews and respective trials. This overview highlights the urgent need for highly homogeneous trials, with clearly reported participants and replicable methods, that in turn allow for the construction of systematic reviews that follow a homogeneous methodology. These reviews have identified solid constructs with several questions raised and limitations noted. We think that it is time to strictly aim for highly replicable and standardized trials/systematic reviews that ultimately will allow multi imaging techniques to be applied in the same conditions. 


\section{References}

Aoki, Y., Inokuchi, R., Suwa, H., \& Aoki, A. (2013). Age-related change of neurochemical abnormality in attentiondeficit hyperactivity disorder: A meta-analysis. Neuroscience \& Biobehavioral Reviews, 37(8), 1692-1701. doi:10.1016/j.neubiorev.2013.04.019

Aron, A. R., \& Poldrack, R. A. (2005). The cognitive neuroscience of response inhibition: Relevance for genetic research in attention-deficit/hyperactivity disorder. Biological Psychiatry, 57(11), 1285-1292. doi:10.1016/j. biopsych.2004.10.026

Boonstra, A. M., Oosterlaan, J., Sergeant, J. A., \& Buitelaar, J. K. (2005). Executive functioning in adult ADHD: A meta-analytic review. Psychological Medicine, 35(8), 1097-1108. doi:10.1017/S003329170500499X

Booth, A., Clarke, M., Ghersi, D., Moher, D., Petticrew, M., \& Stewart, L. (2011). An international registry of systematic-review protocols. The Lancet, 377(9760), 108-109. doi:10.1016/S0140-6736(10)60903-8

Brown, F. C., Roth, R. M., \& Katz, L. J. (2015). Allocentric but not egocentric visual memory difficulties in adults with ADHD may represent cognitive inefficiency. Psychiatry Research, 228(3), 649-658. doi:10.1016/j. psychres.2015.04.051

Bunse, T., Wobrock, T., Strube, W., Padberg, F., Palm, U., Falkai, P., \& Hasan, A. (2014). Motor cortical excitability assessed by transcranial magnetic stimulation in psychiatric disorders: A systematic review. Brain Stimulation, 7(2), 158-169. doi:10.1016/j.brs.2013.08.009

Bush, G., Valera, E. M., \& Seidman, L. J. (2005). Functional neuroimaging of attention-deficit/hyperactivity disorder: A review and suggested future directions. Biological Psychiatry, 57(11), 1273-1284. doi:10.1016/j.biopsych.2005.01.034

Cao, M., Shu, N., Cao, Q., Wang, Y., \& He, Y. (2014). Imaging functional and structural brain connectomics in attention-deficit/hyperactivity disorder. Molecular Neurobiology, 50(3), 1111-1123. doi:10.1007/s12035-0148685-x

Carp, J., \& Compton, R. J. (2009). Alpha power is influenced by performance errors. Psychophysiology, 46(2), 336-343. doi:10.1111/j.1469-8986.2008.00773.x

Castellanos, F. X., \& Acosta, M. T. (2002). El sindrome de deficit de atencion con hiperactividad como expresion de un trastorno funcional organico. Revista De Neurologia, 35(1), 1-11.

Castellanos, F. X., \& Proal, E. (2012). Large-scale brain systems in ADHD: Beyond the prefrontal-striatal model. Trends in Cognitive Sciences, 16(1), 17-26. doi:10.1016/j.tics.2011.11.007

Chen, L., Hu, X., Ouyang, L., He, N., Liao, Y., Liu, Q., ... Gong, Q. (2016). A systematic review and meta-analysis of tract-based spatial statistics studies regarding attention-deficit/hyperactivity disorder. Neuroscience and Biobehavioral Reviews, 68, 838-847. doi:10.1016/j.neubiorev.2016.07.022

Cherkasova, M. V., \& Hechtman, L. (2009). Neuroimaging in attention-deficit hyperactivity disorder: Beyond the frontostriatal circuitry. Canadian Journal of Psychiatry, 54(10), 651-664. doi:10.1177/070674370905401002

Cole, M. W., \& Schneider, W. (2007). The cognitive control network: Integrated cortical regions with dissociable functions. NeuroImage, 37(1), 343-360. doi:10.1016/j.neuroimage.2007.03.071

The Cochrane Collaboration. (2011). Cochrane handbook for systematic reviews of interventions version 5.1.0. In J. P. Higgins, \& S. Green (Eds.).

Cooper, P. S., Wong, A. S. W., Fulham, W. R., Thienel, R., Mansfield, E., Michie, P. T., \& Karayanidis, F. (2015). Theta frontoparietal connectivity associated with proactive and reactive cognitive control processes. NeuroImage, 108, 354-363. doi:10.1016/j.neuroimage.2014.12.028

Cortese, S., Kelly, C., Chabernaud, C., Proal, E., Di Martino, A., Milham, M. P., \& Castellanos, F. X. (2012). Toward systems neuroscience of ADHD: A meta-analysis of 55 fMRI sudies. American Journal of Psychiatry, 169(10), 10381055. doi:10.1176/appi.ajp.2012.11101521

Cubillo, A., Halari, R., Smith, A., Taylor, E., \& Rubia, K. (2012). A review of fronto-striatal and fronto-cortical brain abnormalities in children and adults with Attention Deficit Hyperactivity Disorder (ADHD) and new evidence for dysfunction in adults with ADHD during motivation and attention. Cortex, 48(2), 194-215. doi:10.1016/j. cortex.2011.04.007

Dickstein, S. G., Bannon, K., Xavier Castellanos, F., \& Milham, M. P. (2006). The neural correlates of attention deficit hyperactivity disorder: An ALE meta-analysis. Journal of Child Psychology and Psychiatry and Allied Disciplines, 47 (10), 1051-1062. doi:10.1111/j.1469-7610.2006.01671.x

Durston, S. (2003). A review of the biological bases of ADHD: What have we learned from imaging studies? Mental Retardation and Developmental Disabilities Research Reviews, 9(3), 184-195. doi:10.1002/mrdd.10079

Durston, S., De Zeeuw, P., \& Staal, W. G. (2009). Imaging genetics in ADHD: A focus on cognitive control. Neuroscience and Biobehavioral Reviews, 33(5), 674-689. doi:10.1016/j.neubiorev.2008.08.009

Dutra, T. G., Baltar, A., \& Monte-Silva, K. K. (2016). Motor cortex excitability in attention-deficit hyperactivity disorder (ADHD): A systematic review and meta-analysis. Research in Developmental Disabilities, 56, 1-9. doi:10.1016/j.ridd.2016.01.022 
Eickhoff, S. B., Bzdok, D., Laird, A. R., Kurth, F., \& Fox, P. T. (2012). Activation likelihood estimation meta-analysis revisited. NeuroImage, 59(3), 2349-2361. doi:10.1016/j.neuroimage.2011.09.017

Ellison-Wright, I., Ellison-Wright, Z., \& Bullmore, E. (2008). Structural brain change in attention deficit hyperactivity disorder identified by meta-analysis. BMC Psychiatry, 8, 51. doi:10.1186/1471-244X-8-51

Emond, V., Joyal, C., \& Poissant, H. (2009). Neuroanatomie structurelle et fonctionnelle du trouble déficitaire dattention avec ou sans hyperactivité (TDAH). Encephale, 35(2), 107-114. doi:10.1016/j.encep.2008.01.005

Faraone, S. V., \& Biederman, J. (1998). Neurobiology of attention-deficit hyperactivity disorder. Biological Psychiatry, 44(10), 951-958. doi:10.1016/S0006-3223(98)00240-6

Frodl, T., \& Skokauskas, N. (2012). Meta-analysis of structural MRI studies in children and adults with attention deficit hyperactivity disorder indicates treatment effects. Acta Psychiatrica Scandinavica, 125(2), $114-126$. doi:10.1111/j.1600-0447.2011.01786.x

García Murillo, L., Cortese, S., Anderson, D., Di Martino, A., \& Castellanos, F. X. (2015). Locomotor activity measures in the diagnosis of attention deficit hyperactivity disorder: Meta-analyses and new findings. Journal of Neuroscience Methods, 252, 14-26. doi:10.1016/j.jneumeth.2015.03.001

Germano, G. D., Pinheiro, F. H., Okuda, P. M. M., \& Capellini, S. A. (2013). Visual-motor perception in students with attention deficit with hyperactivity disorder. CoDAS, 25(4), 337-341. doi:10.1590/S2317-17822013000400007

Giedd, J. N., Blumenthal, J., Molloy, E., \& Castellanos, F. X. (2001). Brain imaging of attention deficit/hyperactivity disorder. Annals of the New York Academy of Sciences, 931, 33-49. doi:10.1111/j.1749-6632.2001.tb05772.x

Graziano, P. A., \& Garcia, A. (2016). Attention-deficit hyperactivity disorder and children's emotion dysregulation: A meta-analysis. Clinical Psychology Review. doi:10.1016/j.cpr.2016.04.011

Harding, I. H., Yücel, M., Harrison, B. J., Pantelis, C., \& Breakspear, M. (2015). Effective connectivity within the frontoparietal control network differentiates cognitive control and working memory. NeuroImage, 106, $144-153$. doi:10.1016/j.neuroimage.2014.11.039

Hart, H., Radua, J., Mataix-Cols, D., \& Rubia, K. (2012). Meta-analysis of fMRI studies of timing in attention-deficit hyperactivity disorder (ADHD). Neuroscience and Biobehavioral Reviews, 36(10), 2248-2256. doi:10.1016/j. neubiorev.2012.08.003

Hart, H., Radua, J., Nakao, T., Mataix-Cols, D., \& Rubia, K. (2013). Meta-analysis of functional magnetic resonance imaging studies of inhibition and attention in attention-deficit/hyperactivity disorder: Exploring task-specific, stimulant medication, and age effects. JAMA Psychiatry, 70(2), 185-198. doi:10.1001/jamapsychiatry.2013.277

Herrmann, M. J., Biehl, S. C., Jacob, C., \& Deckert, J. (2010). Neurobiological and psychophysiological correlates of emotional dysregulation in ADHD patients. ADHD Attention Deficit and Hyperactivity Disorders, 2(4), $233-239$. doi:10.1007/s12402-010-0047-6

Hlinka, J., Alexakis, C., Diukova, A., Liddle, P. F., \& Auer, D. P. (2010). Slow EEG pattern predicts reduced intrinsic functional connectivity in the default mode network: An inter-subject analysis. NeuroImage, 53(1), $239-246$. doi:10.1016/j.neuroimage.2010.06.002

Hutchinson, A. D., Mathias, J. L., \& Banich, M. T. (2008). Corpus callosum morphology in children and adolescents with attention deficit hyperactivity disorder: A meta-analytic review. Neuropsychology, 22(3), 341-349. doi:10.1037/ 0894-4105.22.3.341

The Joanna Briggs Institute. (2014). Joanna Briggs Institute Reviewers' Manual: 2014 edition/Supplement. Adelaide, Australia.

Kaiser, M. L., Schoemaker, M. M., Albaret, J. M., \& Geuze, R. H. (2015). What is the evidence of impaired motor skills and motor control among children with attention deficit hyperactivity disorder (ADHD)? Systematic review of the literature. Research in Developmental Disabilities, 36, 338-357. doi:10.1016/j.ridd.2014.09.023

Kelly, A. M. C., Margulies, D. S., \& Castellanos, F. X. (2007). Recent advances in structural and functional brain imaging studies of attention-deficit/hyperactivity disorder. Current Psychiatry Reports, 9(5), 401-407. doi:10.1007/ s11920-007-0052-4

Kofler, M. J., Rapport, M. D., Sarver, D. E., Raiker, J. S., Orban, S. A., Friedman, L. M., \& Kolomeyer, E. G. (2013). Reaction time variability in ADHD: A meta-analytic review of 319 studies. Clinical Psychology Review, 33(6), 795811. doi:10.1016/j.cpr.2013.06.001

Konrad, K., \& Eickhoff, S. B. (2010). Is the ADHD brain wired differently? A review on structural and functional connectivity in attention deficit hyperactivity disorder. Human Brain Mapping, 31(6), 904-916. doi:10.1002/ hbm. 21058

Laird, A. R., Eickhoff, S. B., Kurth, F., Fox, P. M., Uecker, A. M., Turner, J. A., .. Fox, P. T. (2009). ALE meta-analysis workflows via the brainmap database: Progress towards a probabilistic functional brain atlas. Frontiers in Neuroinformatics, 3, 23. doi:10.3389/neuro.11.023.2009

Lansbergen, M. M., Kenemans, J. L., \& Van Engeland, H. (2007). Stroop interference and attention-deficit/hyperactivity disorder: A review and meta-analysis. Neuropsychology, 21(2), 251-262. doi:10.1037/0894-4105.21.2.251

Lei, D., Du, M., Wu, M., Chen, T., Huang, X., Du, X., ... Gong, Q. (2015). Functional MRI reveals different response inhibition between adults and children with ADHD. Neuropsychology, 29(6), 874-881. doi:10.1037/neu0000200 
Lijffijt, M., Kenemans, J. L., Verbaten, M. N., \& Van Engeland, H. (2005). A meta-analytic review of stopping performance in attention-deficit/hyperactivity disorder: Deficient inhibitory motor control? Journal of Abnormal Psychology, 114(2), 216-222. doi:10.1037/0021-843X.114.2.216

Loo, S. K., \& Makeig, S. (2012). Clinical utility of EEG in attention-deficit/hyperactivity disorder: A research update. Neurotherapeutics, 9(3), 569-587. doi:10.1007/s13311-012-0131-z

Mendeley Ltd. (2016). Mendeley desktop. Version, 1.17.6. Elsevier/Amsterdam, The Netherlands.

Mana, S., Paillere Martinot, M. L., \& Martinot, J. L. (2010). Brain imaging findings in children and adolescents with mental disorders: A cross-sectional review. European Psychiatry, 25(6), 345-354. doi:10.1016/j.eurpsy.2010.04.010

Matthews, M., Nigg, J. T., \& Fair, D. A. (2013). Attention deficit hyperactivity disorder. Current Topics in Behavioral Neurosciences, 16, 235-266. doi:10.1007/7854_2013_249

McCarthy, H., Skokauskas, N., \& Frodl, T. (2014). Identifying a consistent pattern of neural function in attention deficit hyperactivity disorder: A meta-analysis. Psychological Medicine, 44(4), 869-880. doi:10.1017/ S0033291713001037

Moher, D., Shamseer, L., Clarke, M., Ghersi, D., Liberati, A., Petticrew, M., ... Stewart, L. A. (2015). Preferred reporting items for systematic review and meta-analysis protocols (PRISMA-P) 2015 statement. Systematic Reviews, 4(1), 1. doi:10.1186/2046-4053-4-1

Montori, V. M., Wilczynski, N. L., Morgan, D., \& Haynes, R. B. (2005). Optimal search strategies for retrieving systematic reviews from Medline: Analytical survey. BMJ (Clinical Research Ed.), 330(7482), 68. doi:10.1136/ bmj.38336.804167.47

Mowinckel, A. M., Pedersen, M. L., Eilertsen, E., \& Biele, G. (2015). A meta-analysis of decision-making and attention in adults with ADHD. Journal of Attention Disorders, 19(5), 355-367. doi:10.1177/1087054714558872

Mullane, J. C., \& Klein, R. M. (2008). Literature review: Visual search by children with and without ADHD. Journal of Attention Disorders, 12(1), 44-53. doi:10.1177/1087054707305116

Nakao, T., Radua, J., Rubia, K., \& Mataix-Cols, D. (2011). Gray matter volume abnormalities in ADHD: Voxel-based meta-analysis exploring the effects of age and stimulant medication. American Journal of Psychiatry, 168(11), 11541163. doi:10.1176/appi.ajp.2011.11020281

Noreika, V., Falter, C. M., \& Rubia, K. (2013). Timing deficits in attention-deficit/hyperactivity disorder (ADHD): Evidence from neurocognitive and neuroimaging studies. Neuropsychologia, 51(2), 235-266. doi:10.1016/j. neuropsychologia.2012.09.036

Paloyelis, Y., Mehta, M. A., Kuntsi, J., \& Asherson, P. (2007). Functional MRI in ADHD: A systematic literature review. Expert Review of Neurotherapeutics, 7(10), 1337-1356. doi:10.1586/14737175.7.10.1337

Pappa, I., Mileva-Seitz, V. R., Bakermans-Kranenburg, M. J., Tiemeier, H., \& Van IJzendoorn, M. H. (2015). The magnificent seven: A quantitative review of dopamine receptor $\mathrm{d} 4$ and its association with child behavior. Neuroscience and Biobehavioral Reviews, 57, 175-186. doi:10.1016/j.neubiorev.2015.08.009

Pauli-Pott, U., \& Becker, K. (2015). Time windows matter in ADHD-related developing neuropsychological basic deficits: A comprehensive review and meta-regression analysis. Neuroscience and Biobehavioral Reviews, 55, 165172. doi:10.1016/j.neubiorev.2015.04.011

Perlov, E., Philipsen, A., Matthies, S., Drieling, T., Maier, S., Bubl, E., ... Tebartz Van, E. L. (2009). Spectroscopic findings in attention-deficit/hyperactivity disorder: Review and meta-analysis. The World Journal of Biological Psychiatry : the Official Journal of the World Federation of Societies of Biological Psychiatry, 10(4 Pt 2), $355-365$. doi:10.1080/15622970802176032

Plichta, M. M., \& Scheres, A. (2014). Ventral-striatal responsiveness during reward anticipation in ADHD and its relation to trait impulsivity in the healthy population: A meta-analytic review of the fMRI literature. Neuroscience and Biobehavioral Reviews, 38, 125-134. doi:10.1016/j.neubiorev.2013.07.012

Polanczyk, G. V., Salum, G. A., Sugaya, L. S., Caye, A., \& Rohde, L. A. (2015). Annual research review: A meta-analysis of the worldwide prevalence of mental disorders in children and adolescents. Journal of Child Psychology and Psychiatry and Allied Disciplines, 56(3), 345-365. doi:10.1111/jcpp.12381

Posner, J., Park, C., \& Wang, Z. (2014). Connecting the dots: A review of resting connectivity MRI studies in attentiondeficit/hyperactivity disorder. Neuropsychology Review, 24(1), 3-15. doi:10.1007/s11065-014-9251-z

Rogers, J. C., \& De Brito, S. A. (2015). Cortical and subcortical gray matter volume in youths with conduct problems a meta-analysis. JAMA Psychiatry, 73, 1-9. doi:10.1001/jamapsychiatry.2015.2423

Rothwell, J. C., Day, B. L., Thompson, P. D., \& Kujirai, T. (2009). Short latency intracortical inhibition: One of the most popular tools in human motor neurophysiology. The Journal of Physiology, 587(1), 11-12. doi:10.1113/ jphysiol.2008.162461

Rubia, K. (2011). "Cool" inferior frontostriatal dysfunction in attention-deficit/hyperactivity disorder versus "hot" ventromedial orbitofrontal-limbic dysfunction in conduct disorder: A review. Biological Psychiatry, 69(12), e69-87. doi:10.1016/j.biopsych.2010.09.023

Rubia, K., Alegria, A., \& Brinson, H. (2014b). Imaging the ADHD brain: Disorder-specificity, medication effects and clinical translation. Expert Review of Neurotherapeutics, 14(5), 519-538. doi:10.1586/14737175.2014.907526 
Rubia, K., Alegria, A. A., \& Brinson, H. (2014a). Brain abnormalities in attention-deficit hyperactivity disorder: A review. Rev Neurol, 58, S3-S18.

Rubia, K., Halari, R., Christakou, A., \& Taylor, E. (2009). Impulsiveness as a timing disturbance: Neurocognitive abnormalities in attention-deficit hyperactivity disorder during temporal processes and normalization with methylphenidate. Philos Trans R Soc Lond B Biol Sci, 364(1525), 1919-1931. doi:10.1098/rstb.2009.0014

Rudo-Hutt, A. S. (2015). Electroencephalography and externalizing behavior: A meta-analysis. Biological Psychology, 105, 1-19. doi:10.1016/j.biopsycho.2014.12.005

Sampson, M., McGowan, J., Cogo, E., Grimshaw, J., Moher, D., \& Lefebvre, C. (2009). An evidence-based practice guideline for the peer review of electronic search strategies. Journal of Clinical Epidemiology, 62(9), $944-952$. doi:10.1016/j.jclinepi.2008.10.012

Schunemann, H. J., Oxman, A. D., Higgins, J. P., Vist, G. E., Glasziou, P. P., \& Guyatt, G. H. (2008). Presenting results and "Summary of Findings" tables. Cochrane Handbook for Systematic Reviews of Interventions: Cochrane Book Series, 335-357. doi:10.1002/9780470712184.ch11

Schwartz, K., \& Verhaeghen, P. (2008). ADHD and Stroop interference from age 9 to age 41 years: A meta-analysis of developmental effects. Psychological Medicine, 38(11), 1607-1616. doi:10.1017/S003329170700267X

Seymour, K. E., Reinblatt, S. P., Benson, L., \& Carnell, S. (2015). Overlapping neurobehavioral circuits in ADHD, obesity, and binge eating: Evidence from neuroimaging research. CNS Spectrums, 20(4), 401-411. doi:10.1017/ S1092852915000383

Sigi Hale, T., Hariri, A. R., \& McCracken, J. T. (2000). Attention-deficit/hyperactivity disorder: Perspectives from neuroimaging. Mental Retardation and Developmental Disabilities Research Reviews, 6(3), 214-219. doi:10.1002/ 1098-2779(2000)6:3<214::AID-MRDD9>3.0.CO;2-M

Smith, V., Devane, D., Begley, C. M., \& Clarke, M. (2011). Methodology in conducting a systematic review of systematic reviews of healthcare interventions. BMC Medical Research Methodology, 11(1), 15. doi:10.1186/14712288-11-15

Snyder, S. M., \& Hall, J. R. (2006). A meta-analysis of quantitative EEG power associated with attention-deficit hyperactivity disorder. Journal of Clinical Neurophysiology, 23(5), 440-455. doi:10.1097/01. wnp.0000221363.12503.78

Sonuga-Barke, E. J. S. (2005). Causal models of attention-deficit/hyperactivity disorder: From common simple deficits to multiple developmental pathways. Biological Psychiatry, 57(11), 1231-1238. doi:10.1016/j.biopsych.2004.09.008

Spencer, A. E., Uchida, M., Kenworthy, T., Keary, C. J., \& Biederman, J. (2014). Glutamatergic dysregulation in pediatric psychiatric disorders. The Journal of Clinical Psychiatry, 75(11), 1226-1241. doi:10.4088/JCP.13r08767

Stanley, J. A., Kipp, H., Greisenegger, E., MacMaster, F. P., Panchalingam, K., Pettegrew, J. W., ... Bukstein, O. G. (2006). Regionally specific alterations in membrane phospholipids in children with ADHD: An in vivo 31P spectroscopy study. Psychiatry Research, 148(2-3), 217-221. doi:10.1016/j.pscychresns.2006.08.003

Swanson, J. M., Kinsbourne, M., Nigg, J., Lanphear, B., Stefanatos, G. A., Volkow, N., ... Wadhwa, P. D. (2007). Etiologic subtypes of attention-deficit/hyperactivity disorder: Brain imaging, molecular genetic and environmental factors and the dopamine hypothesis. Neuropsychology Review, 17(1), 39-59. doi:10.1007/s11065-007-9019-9

Swanson, J. M., Sergeant, J. A., Taylor, E., Sonuga-Barke, E. J. S., Jensen, P. S., \& Cantwell, D. P. (1998). Attentiondeficit hyperactivity disorder and hyperkinetic disorder. Lancet, 351(9100), 429-433. doi:10.1016/S0140-6736(97) 11450-7

Tannock, R. (1998). Attention deficit hyperactivity disorder: Advances in cognitive, neurobiological, and genetic research. Journal of Child Psychology and Psychiatry, and Allied Disciplines, 39(1), 65-99. doi:10.1111/14697610.00304

Tye, C., McLoughlin, G., Kuntsi, J., \& Asherson, P. (2011). Electrophysiological markers of genetic risk for attention deficit hyperactivity disorder. Expert Reviews in Molecular Medicine, 13(March), e9. doi:10.1017/ S1462399411001797

Valera, E. M., Faraone, S. V., Murray, K. E., \& Seidman, L. J. (2007). Meta-analysis of structural imaging findings in attention-deficit/hyperactivity disorder. Biological Psychiatry, 61(12), 1361-1369. doi:10.1016/j. biopsych.2006.06.011

Van Ewijk, H., Heslenfeld, D. J., Zwiers, M. P., Buitelaar, J. K., \& Oosterlaan, J. (2012). Diffusion tensor imaging in attention deficit/hyperactivity disorder: A systematic review and meta-analysis. Neuroscience and Biobehavioral Reviews, 36(4), 1093-1106. doi:10.1016/j.neubiorev.2012.01.003

Van Mourik, R., Oosterlaan, J., \& Sergeant, J. A. (2005). The Stroop revisited: A meta-analysis of interference control in AD/HD. Journal of Child Psychology and Psychiatry and Allied Disciplines, 46(2), 150-165. doi:10.1111/j.14697610.2004.00345.x

Weyandt, L., Swentosky, A., \& Gudmundsdottir, B. G. (2013). Neuroimaging and ADHD: FMRI, PET, DTI findings, and methodological limitations. Developmental Neuropsychology, 38(4), 211-225. doi:10.1080/ 87565641.2013.783833

Wilczynski, N. L., \& Haynes, R. B. (2007). EMBASE search strategies achieved high sensitivity and specificity for retrieving methodologically sound systematic reviews. Journal of Clinical Epidemiology, 60(1), 29-33. doi:10.1016/j. jclinepi.2006.04.001 
Willis, W. G., \& Weiler, M. D. (2005). Neural substrates of childhood attention-deficit/hyperactivity disorder: Electroencephalographic and magnetic resonance imaging evidence. Developmental Neuropsychology, 27(1), 135182. doi:10.1207/s15326942dn2701_6

Yeo, B. T. T., Krienen, F. M., Sepulcre, J., Sabuncu, M. R., Lashkari, D., Hollinshead, M., ... Buckner, R. L. (2011). The organization of the human cerebral cortex estimated by intrinsic functional connectivity. Journal of Neurophysiology, 106(3), 1125-1165. doi:10.1152/jn.00338.2011

Zimmer, L. (2009). Positron emission tomography neuroimaging for a better understanding of the biology of ADHD. Neuropharmacology, 57(7-8), 601-607. doi:10.1016/j.neuropharm.2009.08.001 